\title{
HIROSHIMA, MOKUSATSU AND ALLEGED MISTRANSLATIONS
}

\author{
Boris Naimushin \\ New Bulgarian University, Sofia, Bulgaria
}

Check for

Abstract

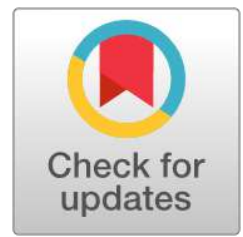

This paper revisits the issue of the importance of context and critical thinking in translation and translation training by examining the linguistic controversy over the translation of the word mokusatsu in the statement of Japan's Prime Minister Suzuki in response to the Potsdam Declaration. There is a widespread belief that the bombing of Hiroshima in August of 1945 was caused by a translation mistake. The author sides with the opposing view, i.e. that such an approach takes one word of the statement out of context in order to shift the focus of the problem from politics to linguistics. The message of the statement is unambiguous when analyzed in its entirety. As a result, it is obvious there was no translation mistake and the bomb was dropped for reasons other than translation quality. Sadly enough, the myth lives on as a textbook example of 'the worst translation mistake in history" whereas it should be taught as an example of probably 'the worst translation myth in history'.

Keywords: translation mistake, translator responsibility, context, mistranslation, myth

\section{Article history:}

Received: 25 February 2021;

Reviewed: 16 March 2021;

Revised: 14 May 2021;

Accepted: 16 May 2021;

Published: 1 June 2021

Copyright (C) 2021 Boris Naimushin

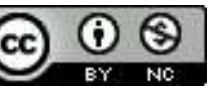

This open access article is published and distributed under a CC BY-NC 4.0 International License which permits non-commercial use, distribution, and reproduction in any medium, provided the original author and source are credited. Permissions beyond the scope of this license may be available at bnaimushin@nbu.bg. If you want to use the work commercially, you must first get the author's permission.

Citation: Naimushin, B. (2021). Hiroshima, Mokusatsu and Alleged Mistranslations. English Studies at NBU, 7(1), 87-96. https://doi.org/10.33919/esnbu.21.1.6

Note: An earlier and partial version of this paper was presented at the X International Conference "Word, Utterance, Text: Cognitive, Pragmatic and Cultural Aspects". Chelyabinsk State University, Russia, 27-29 April 2020.

Boris Naimushin, $\mathrm{PhD}$, is an Associate Professor of Translation and Interpreting in the Department of Foreign Languages and Cultures at the New Bulgarian University. His main research objective lies in the advancement of interpreter training methodology, especially with relation to issues of performance anxiety, public speaking and audience interaction in consecutive and community interpreting. He is the Editor in Chief of English Studies at NBU.

E-mail: bnaimushin@nbu.bg

https://orcid.org/0000-0002-9264-2961 
In translation and interpreting, mistakes (errors, blunders) happen every now and then. Some of them become textbook examples taught to probably every student of translation the world over. If you google "translation mistakes", you will see a great many results with titles such as "Five translation mistakes with serious consequences," or "Top Ten Translation Errors of All Time," or "Nine Little Translation Mistakes That Caused Big Problems," etc. Therefore, students are surely exposed to a lot of information about translation mistakes that have "caused big problems" and even "changed the course of history."

Teachers of translation and interpreting usually do not put this information to doubt and readily incorporate it in their lectures. At least, that is what I used to do when I was making my first steps in teaching translation. I used to teach about the horns of Moses in Saint Jerome's Vulgate and about the mistake of Khrushchev's interpreter who rendered literally the Soviet leader's outburst "We will bury you" and, of course, about the tragic mistranslation of a single word that resulted in the Hiroshima bombing. All this information is readily available in Translation Studies course books as well as in many articles on the Internet.

However, things are not always as straightforward as they may seem. For instance, the horns of Moses in Saint Jerome's Vulgate are not the result of a translation mistake but of a translation dilemma he faced. Jerome was proficient in Hebrew and consulted with Jewish people on his translation. He was perfectly aware of the two possible interpretations of the passage in Exodus 34:29, and made this clear in his Commentary on Ezekiel as well as in the Commentary on the Book of Amos. However, in the first commentary Jerome accepted the interpretation of the Septuagint, i.e. "the appearance of the skin of his face was glorified", while in the second commentary written a few years after his own translation was completed he opted for the literal translation by Aquila, i.e. "his head had horns" (Bertman, 2009, pp. 97-98). He must also have been aware of the fact that "some Jews did believe that Moses was literally horned" (Gilad, 2018). On the other hand, some researchers have argued that this translation has underlying Anti-Semitic intentions (Bertman, 2009). I am confident that students of translation will only benefit from a discussion of this dilemma and the reasons why Jerome turned to the literal translation; otherwise, we end up taking a word out of context 
and presenting Jerome as a laughing stock, which he does not deserve, while missing an excellent learning and teaching opportunity.

The same is true for the widespread myth that the bombing of Hiroshima in August of 1945 was caused by a translation mistake. I support the opposing view, i.e. that it is a myth that served a specific aim of shifting the focus of the problem from politics to linguistics, and that the meaning of the statement is unambiguous, irrespective of the translation of the word mokusatsu (cf. Johnson, 1980; Rhodes, 1986; Bix, 1995; Torkai, 2009). Unfortunately, this myth still lives on as an example of "the worst translation mistake in history", presupposing that an "incompetent translator" was solely responsible for the bombing and that a "competent translator" would have been able to prevent the tragedy. As Chase (1954) put, "One word, misinterpreted”. The thing is that Chase was just repeating the arguments put forward by Kazuo Kawai back in 1950. In fact, Coughlin (1953), Butow (1954), and Chase (1954) took up Kawai's point and cemented the myth that mokusatsu had not been intended to communicate a refusal to surrender.

\section{Taking refuge in alleged mistranslations}

In 1950, Kazuo Kawai, a lecturer in Far Eastern history at Stanford University, whose family moved to the USA in 1908 when he was four, published a short article entitled "Mokusatsu, Japan's Response to the Potsdam Declaration" (Kawai, 1950). In it, he argues that the translation of mokusatsu as "ignore" in the response Japan's Prime Minister Suzuki to the Potsdam Declaration (also known as Proclamation) resulted in the bombing of Hiroshima and asserted that a "correct" translation as "withhold comment" would have prevented the tragedy. Discussing a single word outside context, Kawai performs verbal somersaults in an attempt to convince the international public that Japan never intended to reject the Potsdam Declaration and followed the policy of mokusatsu, which was "quite a different thing from rejection". Kawai went on to argue that this message to the Allies was tragically misunderstood. In addition, he blamed the Russians for their failure to inform their Western Allies of Japan's readiness to surrender.

To support this myth, the third revised edition of the Kenkyusha's New JapaneseEnglish Dictionary added a new meaning of mokusatsu as "remain in a wise and masterly 
inactivity" (Senkichiro, 1954, p. 1129). The two previous editions (1918 and 1931) featured mokusatsu with the meaning of "take no notice of, ignore" and "treat with silent contempt" (e.g., p. 1256 of the 1931 edition). In my opinion, "ignore”, "take no notice of" and "withhold comment" send absolutely the same message in this context. It does not really matter whether you "withhold comment", "remain in a wise and masterly inactivity" or "take no notice" of the ultimatum warning you that any other answer except unconditional surrender would cause "prompt and utter destruction". In other words, if you do not accept it, you reject it. And that is exactly what this statement did. No translator can be blamed for making this "most tragic translation mistake in history" because there was no translation mistake.

More recently, Polizzotti (2018) came up with the interpretation that mokusatsu in the response of Kantaro Suzuki conveyed to Harry Truman as "silent contempt" was actually intended as "No comment. We need more time." First, the translation that Truman received, as can be seen below, said "ignore entirely", not "silent contempt". Second, "we need more time" is a manipulative interpretation in line with the new meaning of mokusatsu added in 1954 ("remain in a wise and masterly inactivity") and is a logical development of Kawai's verbal somersault approach.

The only problem is that all these manipulations are only possible out of context. However, if we look into the full text of the statement translated by a US translator (Dougall, 1960, Document No. 1258), we will see that this statement is impossible to be misunderstood or mistranslated irrespective of the translation of mokusatsu:

Question: "What is the Premier's view regarding the Joint Proclamation by the three countries?"

Answer: "I believe the Joint Proclamation by the three countries is nothing but a rehash of the Cairo Declaration. As for the Government, it does not find any important value in it, and there is no other recourse but to ignore it entirely and resolutely fight for the successful conclusion of this war."

Japan's warring enemies send an ultimatum requiring unconditional surrender. Japan replies that it "does not find any important value in it" and will "resolutely fight for the successful conclusion of this war". The meaning of the part "there is no other recourse but to mokusatsu the Proclamation" is more than obvious, i.e. the Proclamation is 
rejected, ignored, left in silent contempt, etc. In addition, Japan was not asking for more time - can you imagine the enemy telling you, "We need more time and in the meantime we will fight"? On the contrary, the message is clear - at this stage, Japan is not prepared to surrender and is determined to fight on. Period. And there was no mention of any "mistranslation" until 1950, when Kawai came up with his myth finding refuge in an alleged mistranslation.

The vagueness of the Allies' call for unconditional surrender also contributed to the decision to reject the Proclamation (Butow, 1954, p. 136). Both the hawks and doves in Japan's government and military found it impossible to accept the ultimatum requiring unconditional surrender without any comment as to the Emperor's fate. This remained an obstacle to peace even in the wake of Hiroshima, Nagasaki, and the Soviet declaration of war (Sherwin, 1975).

At the same time, the Japanese government was pursuing Soviet mediation for a peace for Japan that would not be unconditional (Butow, 1954, pp. 118-120). President Truman was aware of these efforts from the intercepted and decoded messages between Foreign Minister Togo, one of the leaders of Japan's doves, and Japan's Ambassador to Moscow Sato.

Thus, in the first of the three messages of July 12,1945, Togo asks the Ambassador to convey to the Soviet side a statement on behalf of the Emperor. The statement reiterated that "as long as America and England insist on unconditional surrender, our country has no alternative but to see it [the war] through in an all-out effort for the sake of survival and the honor of the homeland" (Dougall et al., 1960, 761.94/7-2145: Telegram, No. 582). In other words, the Emperor wants the Russians to know that unconditional surrender is unacceptable for Japan and the country is prepared to fight on. And Kawai blames the same Russians for their failure to inform their Western Allies of Japan's readiness to surrender. The same Russians, who, on the one hand, favored unconditional surrender but on the other hand, were angered by the fact that the U.S. did not even consult with them on the Potsdam Proclamation (Byrnes, 1947, p. 207). Togo himself admitted in the third message of July 12 that "the possibility of getting the Soviet Union to join our side and go along with our reasoning is next to nothing" (Dougall et al., 1960, 761.94/7-2145: Telegram No. 584). 
Johnson (1980) notes that if the Prime Minister really meant "no comment," that is not what he said, because "mokusatsu does not imply it, even obliquely." To him, the claim Suzuki's nuance was misunderstood illustrates "the tendency of the Japanese to take refuge in alleged mistranslations."

In his book "The Making of the Atomic Bomb", Rhodes (1986) says, "Historians have debated for years which meaning Suzuki had in mind, but there can hardly be any doubt about the rest of his statement: Japan intended to fight on."

Torikai (2009, p. 35) notes that finding an excuse in an alleged translation mistake is "too naïve a view of international politics" and that "US President Truman would have dropped the bomb with or without mokusatsu."

However, an unclassified article from the US National Security Agency Technical Journal argues that (Rosenbluh, 1968):

"Whoever it was who decided to translate mokusatsu by the one meaning (even though that is the first definition in the dictionary) and didn't add a note that the word might also mean nothing stronger than "to with hold comment" did a horrible disservice to the people who read his translation, people who knew no Japanese, people who would probably never see the original Japanese text and who would never know that there was an ambiguous word used. As a matter of principle, that unknown translator should have pointed out that word has two meanings, thereby enabling others to decide on a suitable course of action."

In other words, according to Harry G. Rosenbluh, a Research Analytic Specialist, Translator-Checker and Cryptologic Linguist at the US National Security Agency, "ignore and fight on" means "reject" but "withhold comment and fight on" means "we need more time". I find it hard to believe that a person can blame an "unknown translator" for a "horrible disservice" after reading the full answer of the Prime Minister. My guess is the expert just repeated the comfortable myth created by Kawai without even bothering to read the original text. The same refers to articles and/or books by Coughlin (1953), Butow (1954), and Chase (1954). Coughlin entitled his article "The Great Mokusatsu Mistake: Was This the Deadliest Error of Our Time?" Chase, who was interested in general semantics and penned books such as "The Tyranny of Words" and "The Power of Words", must have been thrilled by the myth demonstrating the power of a single word. 


\section{Translating the messages}

The Declaration was broadcast by the US Office of War Information on the evening of July 26, first in English and several hours later in Japanese, and also via millions of airdropped leaflets. The Japanese government received the text diplomatically via Swiss intermediaries at 04.30 am on July 27. The censored Japanese translation was released to the public by the Domei News Agency.

On the afternoon of July 27, one day before Prime Minister's press conference, the Domei News Agency was the first to report on the ultimatum. The report informed the Japanese public that, according to authoritative sources, the government would ignore the Declaration and "Japan will prosecute the war in Greater East Asia till the bitter end" (Hasegawa, 2006). Unfortunately, there is no information as to whether this first announcement already used the word mokusatsu. This broadcast was caught and published in the July 28 issue of the New Your Times under the headline "Japanese Cabinet Weighs Ultimatum: Domei Says Empire Will Fight to the End-[Speaker of the House Sam] Rayburn Reports Tokyo Has Made Peace Bid". The article went on to say that the "semi-official Japanese Domei news agency stated today the Allied ultimatum to surrender or meet destruction would be ignored, but official response was awaited as Japan's ruling war lords debated the demand."

On the morning of July 28, Japanese newspapers, including the Asahi Shimbun, wrote about the intention of the government to mokusatsu the declaration as unacceptable. The press conference for the Japanese media was held in the afternoon of the same day.

At the press conference, Prime Minister Suzuki, as expected, announced that Japan ignored (mokusatsu) the Declaration as having no value and that the country would fight till the end. Once again, let us reiterate that the policy of mokusatsu had already been announced the previous day. The following day after the press conference, the US Foreign Broadcast Intelligence Service caught the Domei Agency transmission of this statement in romaji (Latin script); the English translation of this intercepted statement is given above. Later, the Domei News Agency released the official English translation of Prime Minister's statement with mokusatsu rendered as "ignore". 
As we see, translators on both sides of the war lines were involved in the translation of the statement. The American translator(s) rendered into English the intercepted transmission in Japanese translating mokusatsu as "ignore entirely". Hasegawa Saiji, a translator for Domei Press, also translated mokusatsu as "ignore". It is interesting to note that he attended the press conference and distinctly remembered that, when asked whether the government would accept the Potsdam Declaration, Suzuki said: "No comment" (Hasegawa, 2006, p. 168). Another thing worth mentioning is that he once said he should have translated mokusatsu as "no comment," but that nobody in Japan at that time knew the expression (Torikai, 2009, p. 34).

It is a very interesting remark. As we remember, the core of Kawai's reasoning is exactly the existence of a specific policy of mokusatsu, which was "quite a different thing from rejection". And it turns out that "nobody in Japan at that time knew the expression", even an experienced translator at Domei Press. Obviously, there was no "tradition of mokusatsu" in Japanese culture at that time. This policy was announced one day before the release of the official statement and then found its way into the statement. We are not even sure whether Prime Minister Suzuki actually used this word during the press conference and who exactly came up with the idea of this "policy of mokusatsu".

As a result, both the Japanese and the American translators must have had to look up the word in their dictionaries. The dictionaries gave them two very close meanings, i.e. "take no notice of, ignore" and "treat with silent contempt". Both translators opted for "ignore," but nothing would have changed had they chosen to use "treat with silent contempt" instead of "ignore".

\section{Conclusions}

In this paper, we looked at the linguistic controversy over the translation of the word mokusatsu in the statement of Japan's Prime Minister Suzuki in response to the Potsdam Declaration demanding the country's "unconditional surrender," and the circumstances of its translation into English.

The text of the Prime Minister's response clearly and unambiguously shows the position of the government on the issue. Suzuki did reject the Potsdam Declaration and did not ask for more time. Any rendering of mokusatsu as either "ignore" or "reject" or 
"withhold comment" does not change the message of the statement. Consequently, there was no translation mistake and thus no blame for the bombing of Hiroshima can possibly be fixed on any US or Japanese translator. The Potsdam Declaration was rejected, and the A-bomb was dropped for reasons other than translation quality.

The myth of the "most tragic translation mistake in history" takes a single word out of context in order to switch the focus of the problem from politics into linguistics and to exonerate the Japanese government for its rejection of the Potsdam Declaration. Today, it is time to exonerate the translators. Sadly enough, the myth lives on as a textbook example of "the worst translation mistake in history" or "the deadliest error of our time," whereas it should be taught as an example of probably "the worst translation myth in history."

\section{References}

Bertman, S. (2009). The Anti-Semitic Origin of Michelangelo's Horned Moses. Shofar: An Interdisciplinary Journal of Jewish Studies. Summer 2009, 27(4), 95-106. https://doi.org/10.1353/sho.0.0393

Bix, H. P. (1995). Japan's Delayed Surrender: A Reinterpretation. Diplomatic History. 19(2), 197-225. https://doi.org/10.1111/j.1467-7709.1995.tb00656.x

Butow, R. J. C. (1954). Japan's Decision to Surrender. Stanford University Press.

Byrnes, J. (1947). Speaking Frankly. Harper \& Brothers.

Chase, S. (1954). The Power of Words. Harcourt, Brace and Co.

Coughlin, W. J. (1953). "The Great Mokusatsu Mistake: Was This the Deadliest Error of Our Time?" Harper's Magazine, March 1953, 31-40.

Emmerson, J. K. (1978). The Japanese Thread: A life in the U.S. Foreign Service. Holt, Rinehart and Winston.

Dougall, R., Hayes, R. C., Ambach, D. R., Curl, P. V., McDonald, E., Patterson, R. S., Spielman, H., \& Stone, I. A. (Eds.). (1960). Foreign Relations of the United States: Diplomatic Papers, The Conference of Berlin (The Potsdam Conference), 1945, Volume I. United States Government Printing Office.

Dougall, R. (Ed.). (1960). Foreign Relations of the United States: Diplomatic Papers, The Conference of Berlin (The Potsdam Conference), 1945, Volume II. United States Government Printing Office. 
Gilad, E. (2018). Why Even Some Jews Once Believed Moses Had Horns. Jewish World, Mar. 27, 2018. https://www.haaretz.com/jewish/why-even-some-jews-oncebelieved-moses-had-horns-1.5949749

Hasegawa, T. (2006). Racing the Enemy: Stalin, Truman, and the Surrender of Japan. Belknap Press: An Imprint of Harvard University Press. https://doi.org/10.4159/9780674038400

Johnson, Ch. (1980). Omote (Explicit) and Ura (Implicit): Translating Japanese Political Terms. The Journal of Japanese Studies, 6(1), (Winter, 1980), 89-115. https://doi.org/10.2307/132001

Kawai, K. (1950). "Mokusatsu, Japan's Response to the Potsdam Declaration". Pacific Historical Review, 19(4), 409-414. https://doi.org/10.2307/3635822

Marchi, J. J. (1989). Good Translation Might Have Prevented Hiroshima. The New York Times. August 21, 1989, Section A, Page 16.

Polizzotti, M. (2018). Why Mistranslation Matters. The New York Times, 28 July 2018. https://www.nytimes.com/2018/07/28/opinion/sunday/why-mistranslationmatters.html

Rhodes, R. (1986). The Making of the Atomic Bomb: 25th Anniversary Edition. Simon \& Schuster.

Rosenbluh, H. G. (1968). Mokusatsu: One Word, Two Lessons. The NSA Technical Journal. Special Linguistics Issue II. Fall 1968, XIII(4). https://www.nsa.gov/Portals/70/documents/news-features/declassifieddocuments/tech-journals/mokusatsu.pdf

Torikai, K. (2009). Voices of the Invisible Presence. Diplomatic interpreters in post-World War II Japan. John Benjamins Publishing Company. https://doi.org/10.1075/btl.83

Senkichiro, K. (Ed.). (1954). Kenkyusha's New Japanese-English Dictionary. Kenkyusha.

Sherwin, M. J. (1975). A World Destroyed: The Atomic Bomb and the Grand Alliance. Alfred A. Knopf.

\section{Reviewers:}

1. Anonymous

2. Rick Broadaway, Prof., Kanazawa Seiryo University, Japan

\section{Handling Editor:}

Stan Bogdanov, PhD

New Bulgarian University 